\title{
A HYBRID GREY MCDM APPROACH FOR ASSET ALLOCATION: EVIDENCE FROM CHINA'S SHANGHAI STOCK EXCHANGE
}

\author{
Ebenezer Fiifi Emire ATTA MILLS (D) 1, 2, Mavis Agyapomah BAAFI(D)3, \\ Nelson AMOWINE (D) 3 , Kailin ZENG (D) $12^{*}$ \\ ${ }^{1}$ Department of Finance, School of Economics \& Management, \\ Jiangxi University of Science \& Technology, 341000 Ganzhou, China \\ ${ }^{2}$ Ganzhou Academy of Financial Research (GAFR), 341000 Ganzhou, China, \\ ${ }^{3}$ School of Management, Jiangsu University, 212013 Zhenjiang, China
}

Received 14 May 2019; accepted 06 January 2020

\begin{abstract}
Asset allocation is a critical concern for any investor in the financial market. This paper aims to prioritize five randomly selected firms from the top ten stocks by market capitalization of the Shanghai Stock Exchange (SSE) by opting for adequate financial procedures and practical criteria under uncertain conditions. Decision makers want not only the ranking order of stocks but also capital proportions to be allocated. Therefore, this study uses a hybrid multi-criteria decision-making (MCDM) approach comprising of an integrated analytic network process (ANP) and decision making trial and evaluation laboratory (DEMATEL) in a grey environment for optimal portfolio selection to provide both ranking and weighting information for decision makers. Results indicate that return, financial ratios, dividends, and risk are causal criteria group, which are the most influential determinants for obtaining high benefits with regards to stock portfolio selection in SSE. The free float of stocks is the least influencing criterion among all identified criteria of stock portfolio selection of SSE. The Industrial and Commercial Bank of China Ltd. stocks have the highest allocated proportion with the highest priority shown by investors and can be described as a suitable alternative. The practical implications of this research are that the approach, when applied, highlights how the grey system theory minimizes the uncertainties in all stages of decision-making of portfolio selection.
\end{abstract}

Keywords: asset allocation, grey MCDM, grey-ANP, grey-DEMATEL, Shanghai Stock Exchange, China.

JEL Classification: C00, D81, G11.

\section{Introduction}

The framework of optimal portfolio dubbed Modern Portfolio Theory (MPT) can be accredited to seminal works by Markowitz (1952) and Roy (1952). Harry Markowitz (1952)

\footnotetext{
*Corresponding author. E-mail: kailinzeng12@163.com
} 
introduced an approach called the mean-variance (MV) analysis. The optimal portfolio was selected by taking into account two criteria: return and risk. Markowitz preferred one portfolio to the other if it has lower variance and higher expected return. Roy (1952) introduced a safety-first approach that minimizes the shortfall probability to avoid extreme losses. To optimally allocate wealth among assets, a safety-first investor predefines a minimum threshold, below which portfolio wealth, is regarded as disastrous.

Both approaches have become the foundation of extensive studies over the years. M. Simaan, Y. Simaan and Tang (2018) built an estimation error in mean returns into the meanvariance portfolio theory under the assumption that returns on individual assets follow a joint-normal distribution. Proportional transaction costs (Zhu, 2017) that are induced by tax, liquidity costs, and brokerage fees (Kellerer et al., 2000; Wang et al., 2017) are constrained by mean-variance analysis. Ding and Lu (2016) introduced a modified safety-first rule with portfolio selection, including risk-free savings to manage social security trust funds. Atta Mills, Yan, Yu and Wei (2016) proposed a consolidated risk measure based on variance and safety-first principle in a mean-risk portfolio optimization framework. These later advancements of portfolio theory can be classified but not limited to three categories: building models that reflect investor's preferences, incorporating real-world market constraints, and using attributes of diverse areas to deal with practical portfolio strategy problems. These later advancements of portfolio theory are well accepted by investors and fund managers that seek to construct an optimal portfolio with the highest diversification benefit. Portfolio diversification is subjective to many factors that control the portfolio selection criteria, such as investor's judgment, financial ratios, and stock markets, among others.

In helping investors choose an optimal portfolio, investors face various options for investing. Analyzing the present and historical performance of firms via essential criteria can be useful. Using only risk and return is based on the conventional theory of finance but not appealing to behavioral finance. It is imperative to consider other factors that influence portfolio diversification. Investors face different options, and it is essential to consider aspects that affect investors' attitudes like company size, market trends, financial ratios, and dividend, among others. Assessing various criteria that influence stock prices and comparing them to have an optimal portfolio is an intricate and arduous process. Therefore, a multi-criteria decision-making (MCDM) approach can be considered in selecting an optimal portfolio.

In MCDM problems, a decision maker selects or ranks alternatives aligned with contradictory goals or objectives. The decision maker has a set of criteria for stock selection, and these criteria are dependent on interdependent main and resultant determinants. Charouz and Ramík (2010) used a MCDM approach in selecting the optimal portfolio and compared results with mean-variance analysis. Ho, Tsai, Tzeg and Fang (2011) introduced an innovative multi-criteria decision-making approach for selecting an optimal portfolio established on the Capital Asset Pricing Model (CAPM). The decision maker has to compare different criteria and to assess their comparative importance through pairwise comparison amongst each pair of criterion. The decision maker will compare stocks with criteria via a scale and determine the allocation of wealth to each stock.

The inherent nature of financial markets has dismissed the assertion that historical data or performances can predict asset returns. Therefore, researchers have resorted 
to fuzzy set theory to tackle the uncertainty in returns (Vercher et al., 2007). Seçme, Bayrakdaroğlu and Kahraman (2009) used a fuzzy MCDM to assess the performance of banks. Gupta, Mehlawat and Sazena (2013) investigated a three MCDM model for portfolio selection established on ethical and monetarily motivated criteria. They used Analytic Hierarchy Process (AHP) for ethical performance score and fuzzy MCDM technique for financial quality score.

Leung, Hui and Zheng (2003) found out that even though each criterion is not entirely independent, conventional fuzzy MCDM approaches are based on independent assumptions. Analytical Network Process (ANP) method introduced by Saaty (1990) uses a system of pairwise comparisons to measure the weights of the components of the network structure and to rank the alternatives in the decision by considering the interactions between components. However, the handling of inner dependencies is not complete. Therefore, Decision and Evaluation Laboratory (DEMATEL) can be employed in considering the inner dependencies between criteria (Gabus \& Fontela, 1972). DEMATEL is used to identify critical criteria and explore the causal effect relations among the criteria by the visualization of relations through a prominence-causal diagram (Xia et al., 2015).

In portfolio selection, Rezaeian and Akbari (2015) presented a novel approach by combining ANP and DEMATEL for stock portfolio selection in a fuzzy environment to illustrate a better performance for decision makers. However, the fuzzy set theory is limited in dealing with fuzziness (Luthra et al., 2016). Grey system theory offers a comparatively flexible, no parametric and assumptions on distributions, and a broad means to incorporate fuzziness into a system (Dou et al., 2014). Grey system theory is a more robust way of dealing with human judgment about preferences that are difficult to evaluate using deterministic numerical values and helpful in situations described by uncertainty and vagueness. Thus, an MCDM approach in a grey environment provides a robust and user-friendly modeling tool for optimal portfolio selection.

To this end, the purpose of this study is to utilize a hybrid multi-criteria decision-making approach comprising of integrated grey-DEMATEL with grey-ANP for optimal stock portfolio selection. To the best of authors' knowledge, this particular perspective has not been explored. This research aims to prioritize five firms listed on the Shanghai Stock Exchange by opting for adequate financial procedures as well as practical criteria in uncertain conditions. This study highlights how the grey system theory minimizes the uncertainties in all phases of decision-making of portfolio selection. Grey-ANP is used in obtaining a decisive ranking of portfolio alternatives. Grey-DEMATEL is used to tackle inner dependencies between criteria and explore causal effect relations among criteria for portfolio assessment.

A numerical application is pursued to show the applicability of the proposed hybrid approach to the Shanghai Stock Exchange (SSE). The rest of this paper is organized as follows. Section 1 presents the criteria used in the study. Section 2 presents the research methods. In Section 3, the numerical application in selecting an optimal portfolio is pursued. Section 4 is devoted to results and discussion. The final section presents the conclusion of this study. 


\section{Identification of criteria and research framework}

The core problem in portfolio selection is finding a balance or trade-off between return and risks (Markowitz, 1952). Since the mean-variance model, researchers have identified return and risks as essential criteria for the selection and allocation of an optimal portfolio. However, recent developments have led to other equally important factors for portfolio selection (Huang et al., 2008; Cuthbertson \& Nitzsche, 2013; Mandic et al., 2014). In this study, the authors consider several criteria obtained from an in-depth literature review and experts' opinions from SSE. Table 1 outlined the criteria adopted in this study and their corresponding definitions and references. Figure 1 shows the proposed research framework for stock portfolio selection in the Shanghai Stock Exchange. The methodology is based on integrated grey-DEMATEL and grey-ANP for portfolio selection in SSE.

Table 1. Decision making criteria used for stock selection

\begin{tabular}{|c|c|c|}
\hline Criteria & Definitions & References \\
\hline $\begin{array}{l}C_{1}: \\
\text { Conser- } \\
\text { vative } \\
\text { capital } \\
\text { structure }\end{array}$ & $\begin{array}{l}\text { Capital structure shows how a company funds its business } \\
\text { operations, using equity and debt. A conservative capital } \\
\text { structure means that a company manages capital in ways } \\
\text { that create enough short-term liquidity to absorb operating } \\
\text { costs, while also reserving enough finance expansion } \\
\text { without considerably increasing long-term debt. }\end{array}$ & $\begin{array}{l}\text { Expert / Evaluator } \\
\text { opinion for investor } \\
\text { preference }\end{array}$ \\
\hline $\begin{array}{l}C_{2}: \\
\text { Intrinsic } \\
\text { value of } \\
\text { stocks }\end{array}$ & $\begin{array}{l}\text { Value of a company and stock determined through } \\
\text { primary analysis without reference to its market value. In } \\
\text { case of liquidation, it's a measure of the quota of assets } \\
\text { attributable to each share. }\end{array}$ & $\begin{array}{l}\text { (Patel et al., 2015; Gilbert } \\
\text { et al., 2017) }\end{array}$ \\
\hline $\begin{array}{l}C_{3}: \\
\text { Company } \\
\text { size }\end{array}$ & $\begin{array}{l}\text { Typically, the size definition is established on either the } \\
\text { number of employees or revenue turnover, or in some } \\
\text { cases both. Occasionally, it's also based on the size of the } \\
\text { assets on the company's balance sheet. Penny stocks and } \\
\text { small companies add inherent risk. }\end{array}$ & $\begin{array}{l}\text { Expert / Evaluator } \\
\text { opinion for investor } \\
\text { preference }\end{array}$ \\
\hline $\begin{array}{l}C_{4}: \\
\text { Security }\end{array}$ & $\begin{array}{l}\text { A measurement of market or un-diversifiable risk: } \\
\text { uncertainty inherent to the entire market or entire market } \\
\text { segment. }\end{array}$ & $\begin{array}{l}\text { Expert / Evaluator } \\
\text { opinion for investor } \\
\text { preference }\end{array}$ \\
\hline $\begin{array}{l}C_{5}: \\
\text { Financial } \\
\text { ratios }\end{array}$ & $\begin{array}{l}\text { A relative magnitude of two selected numerical values } \\
\text { taken from a firm's financial statements to evaluate the } \\
\text { overall financial condition of a firm. }\end{array}$ & (Capelle-Blancard, 2017) \\
\hline $\begin{array}{l}C_{6}: \\
\text { Risk }\end{array}$ & $\begin{array}{l}\text { The possibility that an investment actual return will be } \\
\text { different than expected. The measure of risks is usually is } \\
\text { the standard deviation of a stock price over a time. }\end{array}$ & $\begin{array}{l}\text { (Atta Mills et al., 2017; } \\
\text { Kelly et al., 2019) }\end{array}$ \\
\hline $\begin{array}{l}C_{7}: \\
\text { Market } \\
\text { trends }\end{array}$ & $\begin{array}{l}\text { The tendency of financial markets to more in a particular } \\
\text { direction over time. }\end{array}$ & $\begin{array}{l}\text { (Ahmed \& Bassiouny, } \\
\text { 2018; Garcia-Lopez et al., } \\
\text { 2018) }\end{array}$ \\
\hline $\begin{array}{l}C_{8}: \text { Free } \\
\text { float of } \\
\text { stocks }\end{array}$ & $\begin{array}{l}\text { Describes the proportion of shares of a publicly traded } \\
\text { firm that is traded in the stock market. Shares held } \\
\text { by investors, other than restricted shares held by firm } \\
\text { insiders. }\end{array}$ & $\begin{array}{l}\text { (Firth et al., 2016; } \\
\text { El-Nader, 2108) }\end{array}$ \\
\hline
\end{tabular}


End of Table 1

\begin{tabular}{|l|l|l|}
\hline \multicolumn{1}{|c|}{ Criteria } & \multicolumn{1}{|c|}{ Definitions } & \multicolumn{1}{c|}{ References } \\
\hline $\begin{array}{l}C_{9}: \\
\text { Dividends }\end{array}$ & $\begin{array}{l}\text { A share of the after-tax earnings of a firm paid regularly } \\
\text { (typically annually) to its shareholders. }\end{array}$ & $\begin{array}{l}\text { (Jakob \& Whitby, 2017; } \\
\text { Karpavičius \& Yu, 2018) }\end{array}$ \\
\hline $\begin{array}{l}C_{10}: \\
\text { Returns }\end{array}$ & $\begin{array}{l}\text { Profit on an investment. It consists of any change in stock } \\
\text { value and interest. It can be measured as percentage of the } \\
\text { invested amount. }\end{array}$ & $\begin{array}{l}\text { (Atta Mills et al., 2017; } \\
\text { He et al., 2019) }\end{array}$ \\
\hline
\end{tabular}

\section{Research methods}

Since in varying financial environment, human judgments about preferences are frequently vague and hard to deduce using deterministic numerical values (Deng, 1982). Grey system theory is valuable in such circumstances described by incomplete information, vagueness,

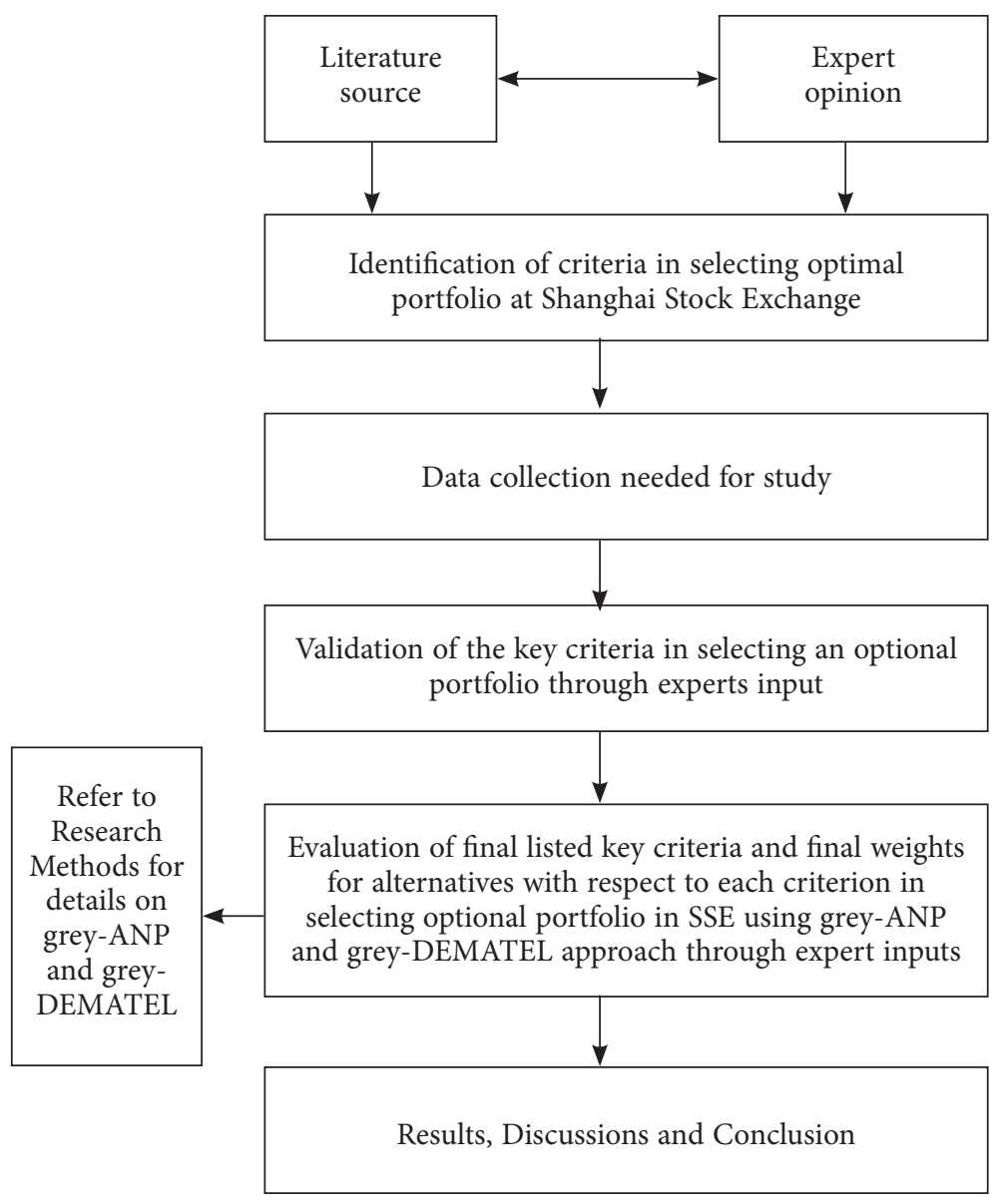

Figure 1. Research flowchart for stock portfolio selection 
uncertainty, partial ignorance, and imprecision. Superior to orthodox statistical modeling techniques, grey system models require small samples to assess the activities of unknown financial systems. Therefore, the integration of grey theory into ANP and DEMATEL produces a robust and user-friendly modeling tool for stock portfolio selection evaluation.

In this section, the authors introduce two methods considered in this study, namely greyANP and grey-DEMATEL, to select the proposed investment portfolio. ANP can be used to solve quantitative and qualitative MCDM that cannot be hierarchically structured when there exist dependence between various levels of elements, and their interactions need to be considered. DEMATEL is an adequate technique for extracting the relationships among stock selection criteria, i.e., indicates the effects among criteria for stock selection.

\subsection{Grey approach}

Deng (1982) proposed a grey approach as a mathematical model from a grey set. A grey approach can produce efficient outputs with small samples and uncertain systems, which is also another benefit as compared to others (Liu \& Qiao, 2014).

In this paper, a grey aggregation method, a variation of Converting Fuzzy data into the Crisp Scores (CFCS) defuzzification method, which has been recognized as an effective tool, will be utilized to deduce crisp scores (Opricovic \& Tzeng, 2003). The grey aggregation method is utilized to offer ranking and weighting information for decision makers under uncertainty. The modified CFCS process, which is established on the minimum and maximum grey number bound, is employed to convert grey numbers into crisp scores. Different approaches, such as the centroid method, exist, but CFCS is more effective at generating crisp scores when compared to others (Rezaeian \& Akbari, 2015).

To present some vital features of grey system theory, some general scheme and procedures for grey systems are first suggested. $x$ is represented as a closed and bounded set of real numbers A grey number, $\varnothing x$, is expressed as an interval with known upper and lower bounds but unknown distribution information for $x$. Let $d$ be the set of decision makers and $I, J$ as the index set of decision-making criteria for stock selection. Let's define $\emptyset x_{i j}^{d}=\left[\emptyset x_{i j}^{d}, \emptyset \bar{x}_{i j}^{d}\right]$ as the grey set for decision maker $d$ that will assess the influence of stock selection criterion $i$ on stock selection criterion $j, \forall d \in D, \forall i \in I$ and $\forall j \in J . \emptyset \underline{x}_{i j}^{d}$ and $\varnothing \bar{x}_{i j}^{d}$ are respectively the lower and upper grey values by a decision maker $d$ for the relationship evaluation of a stock selection criteria $i$ and stock selection criterion $j . T_{i j}^{d}$ is the total normalized crisp value for decision maker $d, \forall d \in D, \forall i \in I$ and $\forall j \in J . z_{i j}^{d}$ is the final crisp value for decision maker $d, \forall d \in D, \forall i \in I$ and $\forall j \in J$. The modified CFCS method involves a three-step algorithm presented as follows:

Step 1: Normalization

$$
\begin{gathered}
\Delta_{\min }^{\max }=\max \emptyset \bar{x}_{i j}^{d}-\min \emptyset \underline{x}_{i j}^{d} ; \\
\underline{x}_{i j}^{d}=\frac{\left[\emptyset \underline{x}_{i j}^{d}-\min \emptyset \underline{x}_{i j}^{d}\right]}{\Delta_{\min }^{\max }} ; \\
\overline{\bar{x}}_{i j}^{d}=\frac{\left[\varnothing \bar{x}_{i j}^{d}-\min \emptyset \underline{x}_{i j}^{d}\right]}{\Delta_{\min }^{\max }} .
\end{gathered}
$$


Step 2: Determining the total normalized crisp value

$$
T_{i j}^{d}=\frac{\left(\left(\emptyset \underline{\underline{x}}_{i j}^{d}\left[1-\emptyset \underline{x}_{i j}^{d}\right]\right)+\left(\varnothing \overline{\bar{x}}_{i j}^{d} \times \varnothing \overline{\bar{x}}_{i j}^{d}\right)\right)}{\left(1-\emptyset \underline{x}_{i j}^{d}+\varnothing \overline{\bar{x}}_{i j}^{d}\right)} .
$$

Step 3: Computing final crisp value

$$
z_{i j}^{d}=\min \emptyset \underline{x}_{i j}^{d}+T_{i j}^{d} \Delta_{\min }^{\max } .
$$

$z_{i j}^{d}$ is a crisp value of comparison between stock selection criteria $i$ and $j$ i.e. the influence of stock selection criteria $i$ on $j$ for the $d$ th decision maker that should be deduced via modified CFCS method. Authors pursue the scope of finding the final weight of each criterion. The aggregated crisp score $z_{i j}$ of comparison between criteria or alternative $i$ and $j$ is computed by

$$
z_{i j}=\sqrt[d]{z_{i j}^{1} \times z_{i j}^{2} \times, \ldots, \times z_{i j}^{d}}
$$

Also, $z_{i j}$ is the aggregated crisp value of comparison between the stock selection criteria $i$ and $j$. Saaty (1980) introduced an approach for calculating the final weight of each stock selection criterion as

$$
W_{i}=\frac{\left(\prod_{j=1}^{m} z_{i j}\right)^{1 / m}}{\left(\sum_{i=1}^{m}\left(\prod_{j=1}^{m} z_{i j}\right)\right)^{1 / m}}, i, j=1,2,3, \ldots, m,
$$

where $m$ is the number of criteria.

\subsection{Grey-ANP}

The Analytic Network Process (ANP) gives a detailed framework to assess a variety of decisions by developing priority scales from individual judgments representative of the dependence between the different level of components of a system and the interaction amongst them (Saaty, 1996). Many problems cannot be structured hierarchically, hence the need for ANP (Saaty, 1990). Unlike the Analytic Hierarchy Process (AHP), ANP allows both interaction and feedback between and within clusters of elements and does not impose a linear structure but instead pursues a network model with outer and inner dependencies. Saaty (1996) suggests the supermatrix technique tackles the interdependence properties among criteria and alternatives. The supermatrix serves as a unifying framework. Please refer to Asan, Soyer, and Serdarasan (2012) for the general form of the supermatrix.

Real-world problems have incomplete information, uncertainty, partial ignorance, and subjective evaluation. It is often difficult to estimate by numerical values, so it is imperative to integrate the grey system with the ANP approach. Grey system theory administers comparatively flexible, no parametric and distribution assumptions, and an appropriate way to 
integrate fuzziness into a problem. Therefore, the integration of grey theory and ANP generates a robust and user-friendly modeling tool for stock portfolio selection evaluation. The grey-ANP based approach in this study is pursued in the following manner:

a) Form a decision network structure.

b) Construct grey pairwise comparisons matrix and employ judgments via linguistic variable defined and provided by authors in Table 2. The grey pairwise comparison matrix done by decision maker $d$ with grey number representatives.

c) Defuzzification of matrices obtained from above via modified CFCS approach in Eq. (1) to Eq. (6).

d) Calculate the final weights for alternatives with regards to objective and crisp integrated values with regards to criteria.

Table 2. Grey linguistic scale of ANP method (source: Authors preference)

\begin{tabular}{|l|c|c|}
\hline \multicolumn{1}{|c|}{ Linguistic variable } & Grey numbers & Normal values \\
\hline Just equal (JE) & {$[0.01,0.3]$} & 0 \\
\hline Weak (WE) & {$[0.3,0.5]$} & 2 \\
\hline Fairly strong (FS) & {$[0.4,0.7]$} & 3 \\
\hline Very strong (VS) & {$[0.5,0.9]$} & 4 \\
\hline Absolute $(\mathrm{AB})$ & {$[0.75,1]$} & 1 \\
\hline
\end{tabular}

The grey-ANP involves three matrices. They are unweighted supermatrix (weight computed via original pairwise comparison), weighted supermatrix (normalized unweighted matrix: sum of weight values of each column is 1) and limit supermatrix (squares the weighted supermatrix many times till all column vectors are of the same value; convergence is achieved).

$$
W_{n}=\left[\begin{array}{ccc}
0 & 0 & 0 \\
W_{21} & W_{22} & 0 \\
0 & W_{32} & I
\end{array}\right]
$$

Figure 2. Supermatrix representation of network structure

Figure 2 is a supermatrix representation of a decision network structure as presented by $W_{n}$ where $W_{21}$ is the final weights for alternatives with respect to objective and crisp integrated values with respect to criteria. $W_{22}$ is the dependence between each criterion. $W_{32}$ is the pairwise comparison matrix of the alternative solution under each criterion, 0 is the independence of the same criterion or between each criterion and $I$ is an identity matrix. $I$ is used to assess outer and inner dependence. Any " $I$ " in supermatrix $W_{n}$ can be substituted with a matrix based on the dependence relationship between groups. In a network structure model like the one studied in this paper, there is a dependence relationship between groups. Therefore, the supermatrix must contain weights of interdependent columns, which is known as unweighted matrix. This unweighted supermatrix $W_{n}$ must be normalized into a weighted supermatrix of the form $W_{n}^{\prime}$ as shown in Figure 3 and convergence effect pursued to develop the limit supermatrix. 


$$
W_{n}^{\prime}=\left[\begin{array}{ccc}
0 & 0 & 0 \\
W_{21} & W_{22} & 0 \\
0 & W_{32} & W_{33}
\end{array}\right]
$$

Figure 3. Weighted supermatrix representation of network structure

The convergence effect is achieved by computing the limit supermatrix $W_{\text {greyANP }}=\lim _{p \rightarrow \infty}\left(W_{n}^{\prime}\right)^{2 p+1}$. The weights of the limit supermatrix $W_{\text {greyANP }}$ will then be used as guideline to rank stocks. Grey-ANP flowchart to assess criteria of stock portfolio selection in SSE is shown in Figure 4.

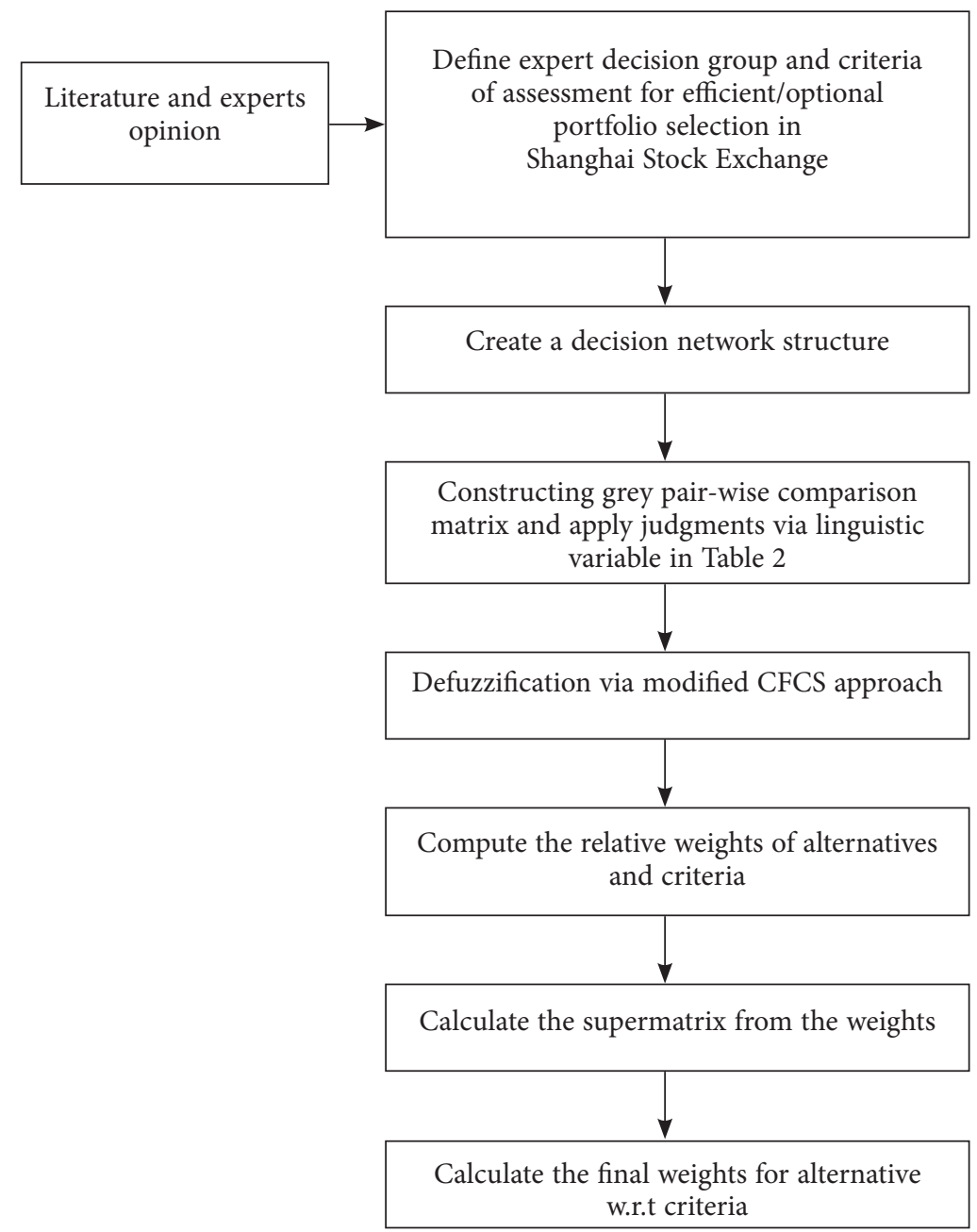

Figure 4. Grey-ANP flowchart to assess criteria of stock portfolio selection in SSE 


\subsection{Grey-DEMATEL}

DEMATEL project was pursued by Battelle Memorial Institute via its Geneva Research Center (Gabus \& Fontela, 1972). DEMATEL technique is a structural modeling approach to identify key enablers and explore the causal-effect relations among the enablers by visualizing the relations via a causal diagram (Xia et al., 2015). The approach explains interdependence relationships and influential effect values among key enablers in the form of a diagraph and causal diagram (Lin, 2013; Haleem et al., 2019).

DEMATEL has been used in areas such as environmental studies, sustainable development, and energy consumption, among others (Abdel-Basset et al., 2018; Kaur et al., 2018; Li \& Mathiyazhagan, 2018). However, classic DEMATEL has been proven to not be adequate in solving problems related to incomplete information, uncertainty, partial ignorance, and subjective evaluation (Bai \& Sarkis, 2011). In tackling the inefficiencies stated above, researchers have resorted to an integrated fuzzy DEMATEL approach (Rezaeian \& Akbari, 2015; Pourjavad \& Shahin, 2018). Nevertheless, this fuzzy method has constraints with fuzziness. To tackle and consider the condition of fuzziness, this study pursues the grey-based DEMATEL approach (Rahimnia et al., 2011; Cui et al., 2019). Grey models are more robust to noise and unavailable modeling information when matched with orthodox methods (Cui et al., 2019; Tian et al., 2019). The authors employ an integrated grey-based DEMATEL approach in this study. Grey-DEMATEL flowchart to assess criteria of stock portfolio selection in SSE is shown in Figure 5.

The grey-DEMATEL used in this study consists of the following steps:

\section{Step 1: Construct grey comparison scale}

Outline a grey pair-wise influence comparison scale that is clearly defined and easy to understand for respondents. In this study, authors employ a five level scale from Xia, Govindan, and Zhu (2015) with the terms and values: $[0,0]=$ No influence, $[0,0.25]=$ Very low influence, $[0.25,0.5]=$ Low influence, $[0.5,0.75]=$ High influence and $[0.75,1]=$ Very high influence. The grey linguistic scales for the respondents' assessments of DEMATEL method are presented in Table 3.

Table 3. Grey comparison scale of DEMATEL approach (source: Xia, Govindan, and Zhu (2015))

\begin{tabular}{|l|c|c|}
\hline \multicolumn{1}{|c|}{ Linguistic term } & Grey values & Normal values \\
\hline No influence $(\mathrm{N})$ & {$[0,0]$} & 0 \\
\hline Very low influence $(\mathrm{VL})$ & {$[0,0.25]$} & 2 \\
\hline Low influence $(\mathrm{L})$ & {$[0.25,0.5]$} & 3 \\
\hline High influence $(\mathrm{H})$ & {$[0.5,0.75]$} & 4 \\
\hline Very high influence $(\mathrm{VH})$ & {$[0.75,1]$} & 1 \\
\hline
\end{tabular}

Step 2: Construct a grey overall direct relation matrix

Direct relation matrix presents degree of effect that one stock selection criterion has on the other. Each expert is tasked to fill such a matrix in order to compare the criteria for stock portfolio selection. Using the importance weights values for all experts or evaluators 
and direct relation matrix for each evaluator, an overall direct relation matrix $Z$ can be deduced. Subsequently, authors used modified CFCS method described earlier to converting grey numbers to crisp numbers. This matrix is $m \times m$ matrix $Z$.

Step 3: Normalization of the direct relation matrix

The normalized direct relation matrix, $R$ can be obtained from Eq. (8) and Eq. (9)

$$
R=Q \times Z \text {; }
$$

$$
Q=\min \left(\frac{1}{\max \sum_{i=1}^{m} z_{i j}}, \quad \frac{1}{\max \sum_{j=1}^{m} z_{i j}}\right), \quad 1 \leq i \leq m, \quad 1 \leq j \leq m,
$$

where $Q$ is normalization factor.

Step 4: Construction of total relation matrix

Total relation matrix denoted by $T$ can be deduced through Eq. (10):

$$
T=R(\boldsymbol{I}-R)^{-1}
$$

where $\boldsymbol{I}$ is $m \times m$ identity matrix.

Step 5: Construct the prominence indexes to obtain a central role matrix

Calculate two indexes, $(\mathrm{W}+\mathrm{H})$ and $(\mathrm{W}-\mathrm{H})$ which are symbolized by cause effect $(\mathrm{W})$ and effect influence $(\mathrm{H})$. These indexes form the degree of prominence and net cause or effect matrix and can be obtained by Eq. (11) and Eq. (12). $(\mathrm{W}+\mathrm{H})$ denote the degree of prominence and net cause or effect, i.e., central role matrix used to assess the criteria of significance for stock portfolio selection factor. $(\mathrm{W}-\mathrm{H})$ denote the degree of relation used to assess the most influential stock portfolio selection factor. An effect and causal illustrative graph can then be provided with $(\mathrm{W}+\mathrm{H})$ and $(\mathrm{W}-\mathrm{H})$ on the horizontal axis and vertical axis respectively. According to $T=\left[t_{i j}\right]_{m \times m} i, j \in\{1,2, \ldots, m\},(\mathrm{W})$ and $(\mathrm{H})$ can be deduced as follows:

$$
\begin{aligned}
& \mathrm{W}=\sum_{j=1}^{m} t_{i j}, \quad i=1,2, \ldots, m ; \\
& \mathrm{H}=\sum_{i=1}^{m} t_{i j}, \quad j=1,2, \ldots, m .
\end{aligned}
$$

\section{Numerical application}

An application of the research methods proposed in the above section is presented here. The authors conveyed their research objectives to five fund managers who are employed in different firms and trade stocks on the Shanghai Stock Exchange. Additionally, the authors disseminated research questions to employees of the Shanghai Stock Exchange: seven members 


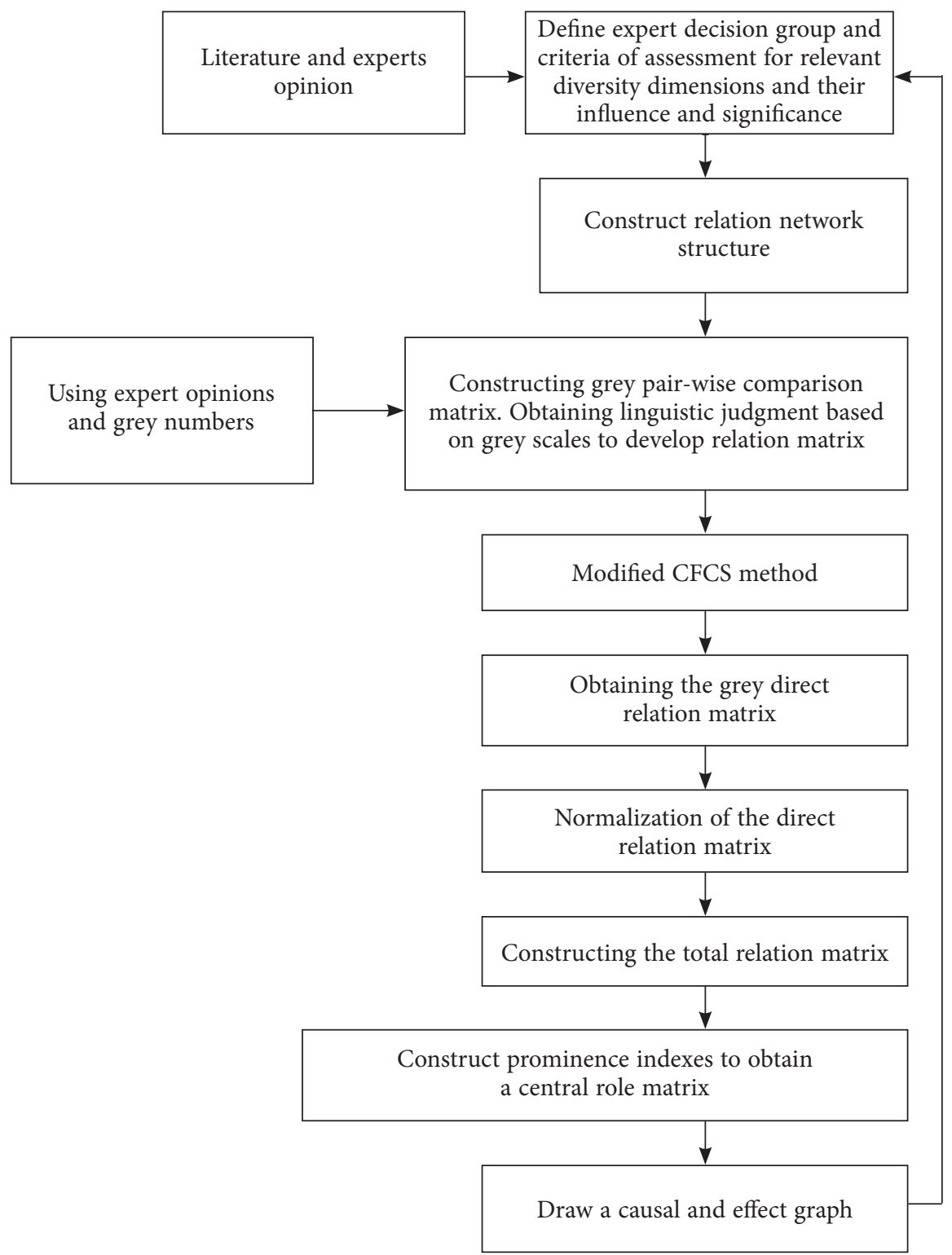

Figure 5. Grey-DEMATEL flowchart to assess criteria of stock portfolio selection in SSE

of the trading management department, five members of the investor education department, and three members of the capital market institute. They all felt the need to find an efficient way of allocating funds considering important influence factors to have an optimal stock portfolio, so each expert or evaluator was enthused to assist us. In this sense, the proposed hybrid grey decision-making method analyzes alternatives, given several criteria to select an optimal portfolio in uncertain environments. To exemplify the propositioned hybrid grey method, there are steps authors need to follow: 
Step 1: Determining the problem statement and objective

The concept of portfolio selection and diversification is imperative in the comprehension of financial decision-making and growth of financial markets. Firms and investors pursue stock portfolio selection as a critical factor in achieving a favorable outcome and a better competitive position: profitable growth, safety net against losses, and strong financial stability and foundation. Hence, optimally allocating funds in uncertain conditions has become an important decision making issue for investors and fund managers. Primarily, this study aims at selecting or ranking alternatives associated with some usually conflicting attributes and allocating funds for the optimal stock portfolio at the Shanghai Stock Exchange.

Step 2: Create a list of stocks to serve as alternative cluster for portfolio selection

This study via random sampling selects five firms listed on the Shanghai Stock Exchange. The selection criterion of the random sampling of stocks is based on Top 10 stocks of largest market capitalization as at January 2019 available from the "Shanghai Stock Exchange (SSE)" (2019) Monthly Market Statistics document ${ }^{1}$. The firms deduced from this evaluation are Industrial and Commercial Bank of China Ltd. $\left(A_{1}\right)$, China National Petroleum Corporation $\left(A_{2}\right)$, China Yangtze Power Co. Ltd. $\left(A_{3}\right)$, China Life Insurance Co. Ltd. $\left(A_{4}\right)$, and Agricultural Bank of China Ltd. $\left(A_{5}\right)$.

\section{Step 3: Determining evaluation criteria}

The evaluation criteria used in this study were obtained from an in-depth literature review and experts' or evaluators' opinions for investor preference. Accordingly, a set of suitable criteria was chosen. Please refer to Table 1 for the evaluation criteria used in this study.

Step 4: Form decision network structure

Evaluation decision network structure is formulated and a more detailed set of stock selection criteria and alternatives within the decision network is delineated in Figure 2.

Step 5: Data Collection and eliciting pairwise comparisons

Questionnaire forms centred on grey-ANP and grey-DEMATEL approaches are structured for the collection of data from evaluators. The judgments of twenty experts aid in obtaining the pairwise comparisons matrices with respect to the objective of the study via completed questionnaires ${ }^{2}$.

Step 6: Data conversion of previous step

In this step, authors convert the data obtained from Step 5 to grey numbers based on the linguistic scales of Table 2, which is defined by authors. The pairwise comparisons are done for the upper part of the main diagonal. Lower parts are calculated using $\varnothing x_{i j}^{d}=\left[\frac{1}{\emptyset \bar{x}_{i j}^{d}}, \frac{1}{\emptyset x_{i j}^{d}}\right]$
and the elements of the diagonal are equal to 1 i.e. $\emptyset x_{i i}^{d}=[1,1]$.

\footnotetext{
${ }^{1}$ Retrieved from http://english2019.sse.com.cn/indices/publications/monthly/

2 Pairwise comparison matrices of experts are available upon request.
} 
Step 7: Defuzzification of matrices obtained from Step 6 of one expert via modified CFCS approach

Table 4 shows defuzzification of matrix obtained from Step 6 of one expert via modified CFCS approach in Eq. (1) to Eq. (5)

Table 4. Final crisp value of one expert

\begin{tabular}{|c|c|c|c|c|c|c|c|c|c|c|}
\hline Objective & $C_{1}$ & $C_{2}$ & $C_{3}$ & $C_{4}$ & $C_{5}$ & $C_{6}$ & $C_{7}$ & $C_{8}$ & $C_{9}$ & $C_{10}$ \\
\hline$C_{1}$ & 1 & 0 & 0 & 2 & 3 & 2 & 3 & 2 & 3 & 2 \\
\hline$C_{2}$ & 0 & 1 & 1 & 2 & 3 & 1 & 2 & 3 & 1 & 3 \\
\hline$C_{3}$ & 0 & 1 & 1 & 2 & 3 & 2 & 2 & 3 & 1 & 2 \\
\hline$C_{4}$ & 2 & 2 & 1 & 1 & 1 & 2 & 1 & 3 & 2 & 3 \\
\hline$C_{5}$ & 3 & 3 & 3 & 1 & 1 & 1 & 2 & 3 & 3 & 2 \\
\hline$C_{6}$ & 2 & 1 & 2 & 2 & 1 & 1 & 2 & 2 & 2 & 3 \\
\hline$C_{7}$ & 3 & 2 & 2 & 1 & 2 & 2 & 1 & 3 & 3 & 2 \\
\hline$C_{8}$ & 2 & 3 & 3 & 3 & 3 & 2 & 3 & 1 & 3 & 2 \\
\hline$C_{9}$ & 3 & 1 & 1 & 2 & 3 & 2 & 3 & 3 & 1 & 1 \\
\hline$C_{10}$ & 2 & 3 & 2 & 3 & 2 & 3 & 2 & 2 & 1 & 1 \\
\hline
\end{tabular}

Step 8: Computing weights using grey-ANP

The matrices obtained from Step 7 are accumulated by Eq. (6) and then using grey-ANP for computing crisp integrated values and final weights for ten criteria with regards to the objective and crisp integrated values and final weights for 5 alternatives with respect to each criterion. The results are displayed in Table 5 and Table 6.

Table 5. Final weights for 10 criteria with respect to objective

\begin{tabular}{|c|c|}
\hline Objective & Weights \\
\hline$C_{1}$ & 0.1021 \\
\hline$C_{2}$ & 0.1092 \\
\hline$C_{3}$ & 0.0876 \\
\hline$C_{4}$ & 0.0880 \\
\hline$C_{5}$ & 0.1202 \\
\hline$C_{6}$ & 0.1101 \\
\hline$C_{7}$ & 0.0712 \\
\hline$C_{8}$ & 0.0624 \\
\hline$C_{9}$ & 0.1104 \\
\hline$C_{10}$ & 0.1388 \\
\hline
\end{tabular}


Table 6. Final weights for 5 stocks with respect to each criterion

\begin{tabular}{|c|c|c|c|c|c|c|}
\hline$C_{1}$ & $A_{1}$ & $A_{2}$ & $A_{3}$ & $A_{4}$ & $A_{5}$ & Weights \\
\hline$A_{1}$ & 1 & 0.9121 & 0.8823 & 0.8854 & 0.8957 & 0.2254 \\
\hline$A_{2}$ & 0.8542 & 1 & 1 & 0.8775 & 0.8760 & 0.2073 \\
\hline$A_{3}$ & 0.7601 & 0.7773 & 1 & 0.8132 & 0.7901 & 0.1856 \\
\hline$A_{4}$ & 0.8551 & 0.8660 & 0.7891 & 1 & 0.8112 & 0.1944 \\
\hline$A_{5}$ & 0.7795 & 0.7598 & 0.7790 & 0.8381 & 1 & 0.1873 \\
\hline $\mathrm{C}_{2}$ & $A_{1}$ & $A_{2}$ & $A_{3}$ & $A_{4}$ & $A_{5}$ & Weights \\
\hline$A_{1}$ & 1 & 0.9219 & 0.9113 & 0.8340 & 0.9010 & 0.2324 \\
\hline$A_{2}$ & 0.8333 & 1 & 0.8687 & 0.8715 & 0.8024 & 0.1972 \\
\hline$A_{3}$ & 0.8001 & 0.8134 & 1 & 0.8008 & 0.7988 & 0.1889 \\
\hline$A_{4}$ & 0.8311 & 0.8413 & 0.8891 & 1 & 0.8112 & 0.1997 \\
\hline$A_{5}$ & 0.7906 & 0.7531 & 0.8112 & 1 & 1 & 0.1818 \\
\hline$C_{3}$ & $A_{1}$ & $A_{2}$ & $A_{3}$ & $A_{4}$ & $A_{5}$ & Weights \\
\hline$A_{1}$ & 1 & 0.9097 & 0.9103 & 0.8083 & 0.8194 & 0.2201 \\
\hline$A_{2}$ & 0.8360 & 1 & 0.9106 & 0.8223 & 0.8921 & 0.2210 \\
\hline$A_{3}$ & 0.8897 & 0.7199 & 1 & 0.8882 & 0.8448 & 0.1999 \\
\hline$A_{4}$ & 0.7538 & 0.7413 & 0.7491 & 1 & 0.7527 & 0.1710 \\
\hline$A_{5}$ & 0.8132 & 0.8391 & 0.8144 & 0.8005 & 1 & 0.1880 \\
\hline$C_{4}$ & $A_{1}$ & $A_{2}$ & $A_{3}$ & $A_{4}$ & $A_{5}$ & Weights \\
\hline$A_{1}$ & 1 & 0.9651 & 0.8491 & 1.0187 & 1.0048 & 0.2401 \\
\hline$A_{2}$ & 0.8626 & 1 & 0.7942 & 0.8541 & 0.7597 & 0.1914 \\
\hline$A_{3}$ & 0.7106 & 1 & 1 & 0.7773 & 0.7140 & 0.1755 \\
\hline$A_{4}$ & 0.8398 & 0.8114 & 0.8084 & 1 & 0.7235 & 0.1874 \\
\hline$A_{5}$ & 0.9002 & 0.8919 & 0.8665 & 0.8723 & 1 & 0.2006 \\
\hline$C_{5}$ & $A_{1}$ & $A_{2}$ & $A_{3}$ & $A_{4}$ & $A_{5}$ & Weights \\
\hline$A_{1}$ & 1 & 0.9240 & 1.0031 & 1.0112 & 1.0196 & 0.2412 \\
\hline$A_{2}$ & 0.8783 & 1 & 0.9087 & 0.9042 & 0.8610 & 0.2011 \\
\hline$A_{3}$ & 0.8307 & 0.8158 & 1 & 0.8046 & 0.8721 & 0.1918 \\
\hline$A_{4}$ & 0.8306 & 0.8216 & 0.8076 & 1 & 0.8014 & 0.1861 \\
\hline$A_{5}$ & 0.7632 & 0.7344 & 0.7160 & 0.7855 & 1 & 0.1798 \\
\hline
\end{tabular}


End of Table 6

\begin{tabular}{|c|c|c|c|c|c|c|}
\hline$C_{6}$ & $A_{1}$ & $A_{2}$ & $A_{3}$ & $A_{4}$ & $A_{5}$ & Weights \\
\hline$A_{1}$ & 1 & 0.9507 & 0.9499 & 0.90585 & 0.9114 & 0.2391 \\
\hline$A_{2}$ & 0.8807 & 1 & 0.87017 & 0.87007 & 0.8693 & 0.1933 \\
\hline$A_{3}$ & 0.8203 & 0.8178 & 1 & 0.8218 & 0.8155 & 0.1872 \\
\hline$A_{4}$ & 0.8776 & 0.8755 & 0.8631 & 1 & 0.8728 & 0.1929 \\
\hline$A_{5}$ & 0.8232 & 0.8204 & 0.8160 & 0.8211 & 1 & 0.1875 \\
\hline$C_{7}$ & $A_{1}$ & $A_{2}$ & $A_{3}$ & $A_{4}$ & $A_{5}$ & Weights \\
\hline$A_{1}$ & 1 & 0.8736 & 0.8834 & 0.8795 & 0.8901 & 0.2001 \\
\hline$A_{2}$ & 0.8479 & 1 & 0.8787 & 0.8726 & 0.8624 & 0.1974 \\
\hline$A_{3}$ & 0.9216 & 0.8934 & 1 & 0.8908 & 0.9067 & 0.2319 \\
\hline$A_{4}$ & 0.8242 & 0.8194 & 0.8230 & 1 & 0.8245 & 0.1886 \\
\hline$A_{5}$ & 0.8146 & 0.8101 & 0.8115 & 0.8014 & 1 & 0.1820 \\
\hline$C_{8}$ & $A_{1}$ & $A_{2}$ & $A_{3}$ & $A_{4}$ & $A_{5}$ & Weights \\
\hline$A_{1}$ & 1 & 0.9134 & 0.9023 & 0.9085 & 0.8957 & 0.2262 \\
\hline$A_{2}$ & 0.8832 & 1 & 0.8961 & 0.8875 & 0.8862 & 0.2059 \\
\hline$A_{3}$ & 0.8119 & 0.8077 & 1 & 0.8143 & 0.8131 & 0.1861 \\
\hline$A_{4}$ & 0.8599 & 0.8672 & 0.8871 & 1 & 0.8658 & 0.1952 \\
\hline$A_{5}$ & 0.8207 & 0.8098 & 0.8190 & 0.8221 & 1 & 0.1866 \\
\hline$C_{9}$ & $A_{1}$ & $A_{2}$ & $A_{3}$ & $A_{4}$ & $A_{5}$ & Weights \\
\hline$A_{1}$ & 1 & 1.0089 & 1.0397 & 1.0040 & 1.0045 & 0.2613 \\
\hline$A_{2}$ & 0.8119 & 0.8109 & 1 & 0.8143 & 0.8131 & 0.1813 \\
\hline$A_{3}$ & 0.7796 & 0.7872 & 1 & 0.7873 & 0.7790 & 0.1760 \\
\hline$A_{4}$ & 0.8871 & 0.8699 & 0.8746 & 1 & 0.8448 & 0.1804 \\
\hline$A_{5}$ & 0.8908 & 0.8886 & 0.8834 & 0.8901 & 1 & 0.2010 \\
\hline$C_{10}$ & $A_{1}$ & $A_{2}$ & $A_{3}$ & $A_{4}$ & $A_{5}$ & Weights \\
\hline$A_{1}$ & 1 & 0.9088 & 0.9022 & 0.9008 & 0.8910 & 0.2013 \\
\hline$A_{2}$ & 0.9823 & 1 & 1.0196 & 0.9742 & 0.9910 & 0.2401 \\
\hline$A_{3}$ & 0.8704 & 0.8678 & 1 & 1 & 0.8714 & 0.1915 \\
\hline$A_{4}$ & 0.8296 & 0.8214 & 1 & 1 & 0.8212 & 0.1859 \\
\hline$A_{5}$ & 0.8199 & 0.8137 & 0.8135 & 0.8140 & 1 & 0.1812 \\
\hline
\end{tabular}


Step 9: Data Collection in relation to criteria based on inner relation

Utilizing questionnaires, pair-wise comparisons are distinctly determined based on linguistic terms. Following accepted practice, authors apportioned appropriate importance weights to each expert based on their functions, skill, and job experience with the stock market.

Step 10: Data conversion from Step 9 to grey numbers centred on grey comparison scale in Table 3 to form direct relation matrix

Step 11: Defuzzification of matrices obtained from Step 10 via modified CFCS approach

Step 12: Aggregation of matrices of previous step using geometric average

Using importance weights values for all evaluators and direct relation matrix for each evaluator, an overall direct-relation of matrix $Z$ can be deduced. Results of Steps 9 to 12 are shown in Table 7 as the overall direct relation matrix.

Table 7. Overall direct relation matrix

\begin{tabular}{|c|c|c|c|c|c|c|c|c|c|c|}
\hline $\begin{array}{c}\text { Objec- } \\
\text { tive }\end{array}$ & $C_{1}$ & $C_{2}$ & $C_{3}$ & $C_{4}$ & $C_{5}$ & $C_{6}$ & $C_{7}$ & $C_{8}$ & $C_{9}$ & $C_{10}$ \\
\hline$C_{1}$ & 0 & 0.4626 & 0.2451 & 0.1151 & 0.3720 & 0.2430 & 0.2732 & 0.3686 & 0.1394 & 0.3388 \\
\hline$C_{2}$ & 0.1552 & 0 & 0.5798 & 0.2327 & 0.3388 & 0.3388 & 0.3454 & 0.0525 & 0.2155 & 0.0510 \\
\hline$C_{3}$ & 0.1919 & 0.1569 & 0 & 0.2511 & 0.1812 & 0.1540 & 0.4992 & 0.7258 & 0.7545 & 0.2159 \\
\hline$C_{4}$ & 0.4120 & 0.3320 & 0.3320 & 0 & 0.1812 & 0.1013 & 0.3772 & 0.1804 & 0.1804 & 0.7660 \\
\hline$C_{5}$ & 0.3729 & 0.7712 & 0.6218 & 0.0555 & 0 & 0.5600 & 0.5795 & 0.5338 & 0.4642 & 0.2136 \\
\hline$C_{6}$ & 0.6293 & 0.2210 & 0.3281 & 0.7182 & 0.3692 & 0 & 0.3518 & 0.2885 & 0.5065 & 0.7326 \\
\hline$C_{7}$ & 0.5874 & 0.4493 & 0.0749 & 0.7283 & 0.3818 & 0.6898 & 0 & 0.2994 & 0.4937 & 0.7318 \\
\hline$C_{8}$ & 0.1845 & 0.3024 & 0.1908 & 0.2914 & 0.3529 & 0.3529 & 0.0866 & 0 & 0.4645 & 0.2561 \\
\hline$C_{9}$ & 0.2311 & 0.2324 & 0.1656 & 0.6212 & 0.4517 & 0.6640 & 0.5962 & 0.1191 & 0 & 0.3203 \\
\hline$C_{10}$ & 0.4573 & 0.2324 & 0.1262 & 0.6218 & 0.4820 & 0.6107 & 0.5342 & 0.1424 & 0.1609 & 0 \\
\hline
\end{tabular}

Step 13: Ranking criteria and specifying causal and effect group using grey-DEMATEL approach

The normalized direct relation matrix $R$ can be computed by Eq. (8) and Eq. (9) as shown in Table 8. The total direct relation matrix $T$ was calculated by Eq. (10) and displayed as Table 9. 
Table 8. Normalized direct relation matrix.

\begin{tabular}{|c|c|c|c|c|c|c|c|c|c|c|}
\hline & $C_{1}$ & $C_{2}$ & $C_{3}$ & $C_{4}$ & $C_{5}$ & $C_{6}$ & $C_{7}$ & $C_{8}$ & $C_{9}$ & $C_{10}$ \\
\hline$C_{1}$ & 0 & 0.0352 & 0.0134 & 0.0010 & 0.0262 & 0.0135 & 0.0167 & 0.0257 & 0.0014 & 0.0237 \\
\hline$C_{2}$ & 0.0016 & 0 & 0.0468 & 0.0121 & 0.0237 & 0.0237 & 0.0233 & 0.0525 & 0.0099 & 0.0510 \\
\hline$C_{3}$ & 0.1919 & 0.0017 & 0 & 0.0150 & 0.0019 & 0.0016 & 0.0387 & 0.0618 & 0.0642 & 0.0194 \\
\hline$C_{4}$ & 0.0301 & 0.0223 & 0.0223 & 0 & 0.0018 & 0.0012 & 0.0259 & 0.0019 & 0.0019 & 0.0543 \\
\hline$C_{5}$ & 0.0261 & 0.0675 & 0.0510 & 0.0555 & 0 & 0.0452 & 0.0467 & 0.0421 & 0.0353 & 0.0190 \\
\hline$C_{6}$ & 0.0518 & 0.0123 & 0.0216 & 0.0607 & 0.0258 & 0 & 0.0248 & 0.0179 & 0.0399 & 0.0631 \\
\hline$C_{7}$ & 0.0476 & 0.0337 & 0.0749 & 0.0613 & 0.0271 & 0.0578 & 0 & 0.0181 & 0.0382 & 0.0628 \\
\hline$C_{8}$ & 0.0017 & 0.0191 & 0.0018 & 0.0179 & 0.0243 & 0.0243 & 0.0010 & 0 & 0.0353 & 0.0144 \\
\hline$C_{9}$ & 0.0121 & 0.0123 & 0.0017 & 0.0513 & 0.0340 & 0.0553 & 0.0482 & 0.0012 & 0 & 0.0210 \\
\hline$C_{10}$ & 0.0346 & 0.0123 & 0.0013 & 0.0519 & 0.0371 & 0.0501 & 0.0421 & 0.0015 & 0.1609 & 0 \\
\hline
\end{tabular}

Table 9. Total direct relation matrix $T$

\begin{tabular}{|c|c|c|c|c|c|c|c|c|c|c|c|}
\hline & $C_{1}$ & $C_{2}$ & $C_{3}$ & $C_{4}$ & $C_{5}$ & $C_{6}$ & $C_{7}$ & $C_{8}$ & $C_{9}$ & $C_{10}$ & $\mathrm{~W}$ \\
\hline$C_{1}$ & 0.0799 & 0.1526 & 0.1943 & 0.1416 & 0.0542 & 0.0585 & 0.1508 & 0.0682 & 0.0744 & 0.0764 & 1.0509 \\
\hline$C_{2}$ & 0.1912 & 0.0746 & 0.2074 & 0.1409 & 0.0385 & 0.0988 & 0.1288 & 0.0644 & 0.0445 & 0.0851 & 1.0742 \\
\hline$C_{3}$ & 0.1619 & 0.1933 & 0.0982 & 0.1854 & 0.0548 & 0.0433 & 0.1314 & 0.0707 & 0.0657 & 0.0688 & 1.0735 \\
\hline$C_{4}$ & 0.1828 & 0.1614 & 0.2182 & 0.1186 & 0.0551 & 0.0615 & 0.0971 & 0.0701 & 0.1149 & 0.1688 & 1.2485 \\
\hline$C_{5}$ & 0.1434 & 0.1147 & 0.1252 & 0.1703 & 0.0411 & 0.0735 & 0.1552 & 0.1511 & 0.1229 & 0.1634 & 1.2608 \\
\hline$C_{6}$ & 0.0729 & 0.0335 & 0.0058 & 0.0721 & 0.0439 & 0.6194 & 0.0693 & 0.0612 & 0.0616 & 0.1238 & 1.1635 \\
\hline$C_{7}$ & 0.1037 & 0.1386 & 0.1612 & 0.1879 & 0.1036 & 0.0421 & 0.0777 & 0.1829 & 0.1239 & 0.2122 & 1.3338 \\
\hline$C_{8}$ & 0.0408 & 0.0547 & 0.0505 & 0.0715 & 0.0442 & 0.0275 & 0.0675 & 0.0489 & 0.0835 & 0.1597 & 0.6488 \\
\hline$C_{9}$ & 0.0911 & 0.0948 & 0.1519 & 0.1405 & 0.0414 & 0.0585 & 0.0903 & 0.0784 & 0.0352 & 0.0872 & 0.8693 \\
\hline$C_{10}$ & 0.1081 & 0.0703 & 0.0732 & 0.1182 & 0.5164 & 0.0527 & 0.6086 & 0.1482 & 0.0522 & 0.0155 & 1.7634 \\
\hline $\mathrm{H}$ & 1.1758 & 1.0885 & 1.2859 & 1.3470 & 0.9932 & 1.1358 & 1.5767 & 0.9441 & 0.7788 & 1.1609 & \\
\hline
\end{tabular}

From the total direct relation matrix, this study can obtain degree of prominence and net cause-effect values using Eq. (11) and Eq. (12) as displayed in Table 10.

Each $(\mathrm{W}+\mathrm{H})$ represent the degree of prominence and net cause-effect values used to evaluate the degree of importance/significance for stock portfolio selection criteria. Also, each $(\mathrm{W}-\mathrm{H})$ represent the degree of relation used to assess the most influential stock 
portfolio selection criteria. A prominence-causal diagram shown in Figure 6 highlights the influence of various stock portfolio selection criteria on others.

Table 10. Degree of prominence and net cause-effect values for stock selection

\begin{tabular}{|c|c|c|c|c|}
\hline & $\mathrm{W}+\mathrm{H}$ & Ranking & $\mathrm{W}-\mathrm{H}$ & Ranking \\
\hline$C_{1}$ & 2.2267 & 7 & -0.1249 & 7 \\
\hline$C_{2}$ & 2.1627 & 8 & -0.0143 & 5 \\
\hline$C_{3}$ & 2.3594 & 4 & -0.2124 & 8 \\
\hline$C_{4}$ & 2.5955 & 3 & -0.0985 & 6 \\
\hline$C_{5}$ & 2.254 & 6 & 0.2676 & 2 \\
\hline$C_{6}$ & 2.2993 & 5 & 0.0277 & 4 \\
\hline$C_{7}$ & 2.9105 & 2 & -0.2429 & 9 \\
\hline$C_{8}$ & 1.5929 & 10 & -0.2953 & 10 \\
\hline$C_{9}$ & 1.6481 & 9 & 0.0905 & 1 \\
\hline$C_{10}$ & 2.9243 & 1 & 0.6025 & \\
\hline
\end{tabular}

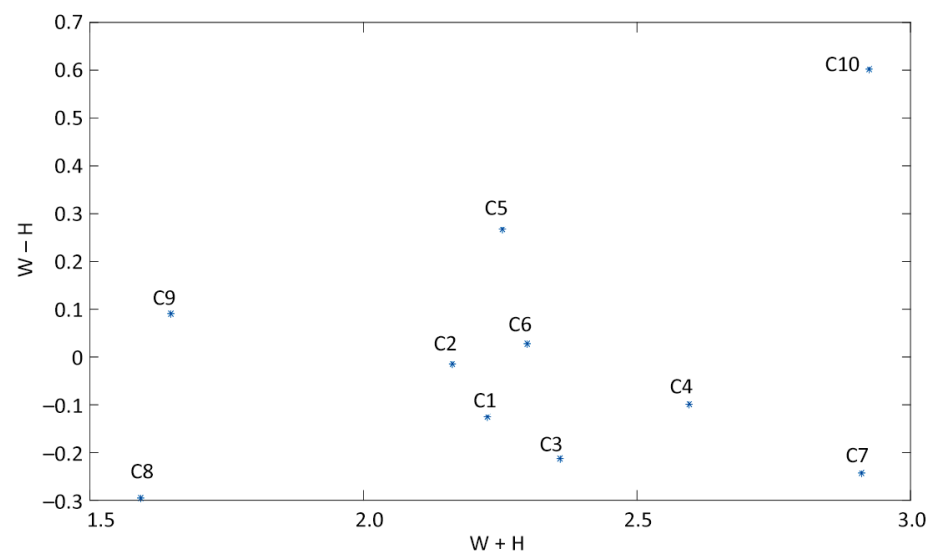

Figure 6. The prominence-causal diagram between criteria

Step 14: Integration of grey-DEMATEL and grey-ANP methods

The total relation deduced from grey-DEMATEL approach is normalized and inserted into the unweighted supermatrix (Wu \& Hung, 2008). Unweighted supermatrix consists of final weights for five stocks with regards to each criterion, final weights for criteria with respect to objective and normalized total relation matrix. By using results from grey-DEMATEL (normalized total relation matrix) and grey-ANP (weights from Table 5 and Table 6), the unweighted supermatrix is computed and available upon request. 
Step 15: Ranking stocks for best investment

At this phase, final weights of stock alternatives will be computed and stocks ranked through computation of limit supermatrix. To meet mathematical logic, the unweighted supermatrix must be normalized so that the sum of the column vectors is equal to 1 . Weighted supermatrix $^{3}$ is obtained by normalizing columns of unweighted supermatrix ${ }^{2}$. To obtain limit supermatrix, weighted supermatrix is raised to the $62^{\text {nd }}$ power. Limit supermatrix can be deduced from "Super Decisions" software and global priorities of all criteria and stock alternatives can be obtained. Table 11 provides the results.

Table 11. Limit supermatrix

\begin{tabular}{|l|c|c|c|c|c|c|c|c|c|c|c|}
\hline & $C_{1}$ & $C_{2}$ & $C_{3}$ & $C_{4}$ & $C_{5}$ & $C_{6}$ & $C_{7}$ & $C_{8}$ & $C_{9}$ & $C_{10}$ & Objective \\
\hline$A_{1}$ & 0.1603 & 0.1603 & 0.1603 & 0.1603 & 0.1603 & 0.1603 & 0.1603 & 0.1603 & 0.1603 & 0.1603 & 0.1603 \\
\hline$A_{2}$ & 0.1406 & 0.1406 & 0.1406 & 0.1406 & 0.1406 & 0.1406 & 0.1406 & 0.1406 & 0.1406 & 0.1406 & 0.1406 \\
\hline$A_{3}$ & 0.1345 & 0.1345 & 0.1345 & 0.1345 & 0.1345 & 0.1345 & 0.1345 & 0.1345 & 0.1345 & 0.1345 & 0.1345 \\
\hline$A_{4}$ & 0.1324 & 0.1324 & 0.1324 & 0.1324 & 0.1324 & 0.1324 & 0.1324 & 0.1324 & 0.1324 & 0.1324 & 0.1324 \\
\hline$A_{5}$ & 0.1285 & 0.1285 & 0.1285 & 0.1285 & 0.1285 & 0.1285 & 0.1285 & 0.1285 & 0.1285 & 0.1285 & 0.1285 \\
\hline$C_{1}$ & 0.0309 & 0.0278 & 0.0278 & 0.0278 & 0.0278 & 0.0278 & 0.0278 & 0.0278 & 0.0278 & 0.0278 & 0.0278 \\
\hline$C_{2}$ & 0.0311 & 0.0311 & 0.0311 & 0.0311 & 0.0311 & 0.0311 & 0.0311 & 0.0311 & 0.0311 & 0.0311 & 0.0311 \\
\hline$C_{3}$ & 0.0307 & 0.0307 & 0.0307 & 0.0307 & 0.0307 & 0.0307 & 0.0307 & 0.0307 & 0.0307 & 0.0307 & 0.0307 \\
\hline$C_{4}$ & 0.0310 & 0.0310 & 0.0310 & 0.0310 & 0.0310 & 0.0310 & 0.0310 & 0.0310 & 0.0310 & 0.0310 & 0.0310 \\
\hline$C_{5}$ & 0.0323 & 0.0323 & 0.0323 & 0.0323 & 0.0323 & 0.0323 & 0.0323 & 0.0323 & 0.0323 & 0.0323 & 0.0323 \\
\hline$C_{6}$ & 0.0321 & 0.0321 & 0.0321 & 0.0321 & 0.0321 & 0.0321 & 0.0321 & 0.0321 & 0.0321 & 0.0321 & 0.0321 \\
\hline$C_{7}$ & 0.0278 & 0.0278 & 0.0278 & 0.0278 & 0.0278 & 0.0278 & 0.0278 & 0.0278 & 0.0278 & 0.0278 & 0.0278 \\
\hline$C_{8}$ & 0.0234 & 0.0234 & 0.0234 & 0.0234 & 0.0234 & 0.0234 & 0.0234 & 0.0234 & 0.0234 & 0.0234 & 0.0234 \\
\hline$C_{9}$ & 0.0316 & 0.0316 & 0.0316 & 0.0316 & 0.0316 & 0.0316 & 0.0316 & 0.0316 & 0.0316 & 0.0316 & 0.0316 \\
\hline$C_{10}$ & 0.0328 & 0.0328 & 0.0328 & 0.0328 & 0.0328 & 0.0328 & 0.0328 & 0.0328 & 0.0328 & 0.0328 & 0.0328 \\
\hline
\end{tabular}

The limit supermatrix demonstrates which criteria investors of SSE are concerned with and the order of importance in terms of allocation of the stocks. The higher the value, the more stock allocation proportions and the higher concern shown by investors with respect to the stock selection criteria.

In allocating weights for stocks in portfolio selection, authors calculate the preponderant vectors of five alternative solutions by using the final weights for five stocks with respect to each criterion (refer to Table 6) and the final weights for ten criteria with respect to objective. Thus,

\footnotetext{
$\overline{3}$ Omitted results are available from the authors upon request.
} 


$$
\left[\begin{array}{llllllllll}
0.2254 & 0.2324 & 0.2201 & 0.2401 & 0.2412 & 0.2391 & 0.2001 & 0.2262 & 0.2613 & 0.2013 \\
0.2073 & 0.1972 & 0.2210 & 0.1914 & 0.2011 & 0.1933 & 0.1974 & 0.2059 & 0.1813 & 0.2401 \\
0.1856 & 0.1889 & 0.1999 & 0.1755 & 0.1918 & 0.1872 & 0.2319 & 0.1861 & 0.1760 & 0.1915 \\
0.1944 & 0.1997 & 0.1710 & 0.1874 & 0.1861 & 0.1929 & 0.1886 & 0.1952 & 0.1804 & 0.1859 \\
0.1873 & 0.1818 & 0.1880 & 0.2006 & 0.1798 & 0.1875 & 0.1820 & 0.1866 & 0.2010 & 0.1812
\end{array}\right]\left[\begin{array}{l}
0.1021 \\
0.1092 \\
0.0876 \\
0.0880 \\
0.1202 \\
0.1101 \\
0.0712 \\
0.0624 \\
0.1104 \\
0.1388
\end{array}\right] .
$$

The above equation deduces the allocation proportions for each randomly selected stock considered for the study. An optimal way of allocating capital to the stocks considered in this study is as follows: Industrial and Commercial Bank of China Ltd. (22.9\%), China National Petroleum Corporation (20.5\%), China Yangtze Power Co. Ltd. (19.1\%), China Life Insurance Co. Ltd. (18.8\%), and Agricultural Bank of China Co. Ltd. (18.7\%).

\section{Results and discussion}

The overall direct relation matrix completed by twenty experts is shown in Table 7. Based on the management position, knowledge, and experience, this study assigned importance weights. Subsequently, this research uses the approach introduced in the research methods section. Table 9 presents the total direct relation matrix. The degree of central role matrix, which harbors prominence and causal values, are shown in Table 10.

The higher the prominence value $(\mathrm{W}+\mathrm{H})$, the higher the significance of criteria. Using degree of significance or importance $(\mathrm{W}+\mathrm{H})$, the order of significance or importance of the stock portfolio selection criteria in SSE are identified as follows: $C_{10}>C_{7}>C_{4}>C_{3}>C_{6}>C_{5}>C_{1}>C_{2}>C_{9}>C_{8}$. The degree of importance/significance signifies the importance degree of each criterion or the 'prominence' of each criterion.

To avoid biasness as a result of assigned weights to evaluators, the authors pursue the scope of sensitivity analysis. Our aim is to test the robustness of results by performing sensitivity analysis for an expert or evaluator with the highest weight. Authors report similarity in the final sensitivity analysis results and the grey-DEMATEL prominence-causal diagram. As shown in Figure 6, $C_{10}$ and $C_{5}$ have the first and second highest values correspondingly. Also, $C_{7}$ and $C_{8}$ have the lowest values. These values are common in both prominence-causal graphs. Some differences are noticeable in the intermediate criteria in the effect group $\left(C_{4}\right.$ and $C_{1}$ ) but the final sensitivity analysis result (Figure 7) is in line with the grey-DEMATEL prominence-causal diagram.

The degree of importance or significance does not offer insight to investors and other stakeholders. The degree of influence $(\mathrm{W}-\mathrm{H})$ indicates the net effect that a stock selection criterion provides to the system in this research. When the value of the degree of influence is negative for a stock selection criterion, then the criterion is assumed to be in effect group. When the value of the degree of influence is positive, then it's in cause group (most influential). 


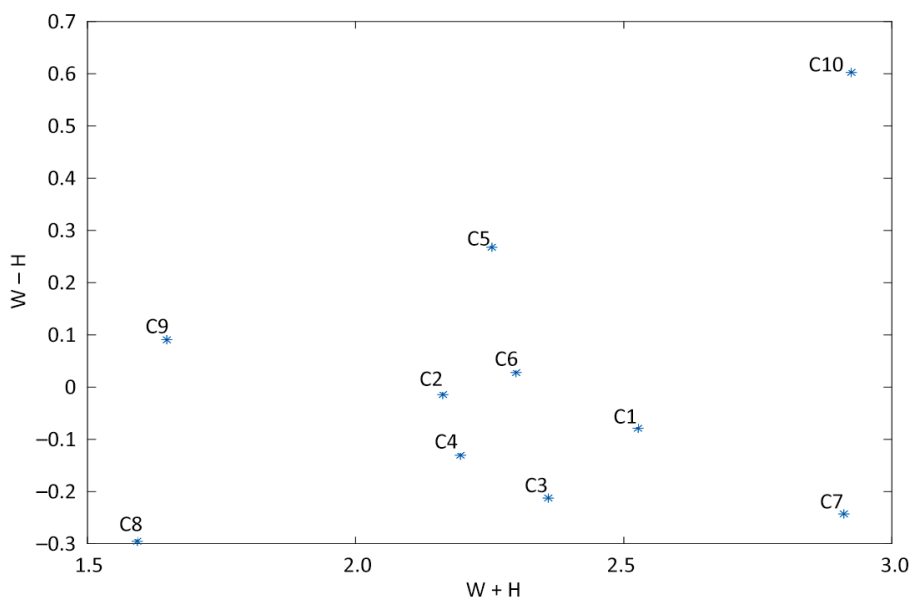

Figure 7. The prominence-causal diagram for sensitivity analysis

According to Figure 6, the causal criteria are $C_{10}>C_{5}>C_{9}>C_{6}$. In these causal factors, $C_{10}$ (return) is the top criterion of the cause group, which shows that return is the primary causal factor. As illustrated by MV analysis, return is a major criterion for portfolio selection and the results from this study indicate that both return and risk aside financial ratios and dividends are influential in stock portfolio selection of SSE. Effect criteria can be sorted as follows: $C_{2}>C_{4}>C_{1}>C_{3}>C_{7}>C_{8}$. The six criteria are influenced by causal criteria. The intrinsic value of stocks is nearest to the cause group and has the least influence by causal criteria. The free float of stocks is the least influencing criterion among all identified criteria of stock portfolio selection of SSE. If the decision maker wants to attain high rewards, it would be essential to control and be attentive to the causal criteria group. This is because the causal criteria exemplify the influencing criteria, while the effect criteria represent the influenced criteria.

Critical or analytical criteria with a high degree of importance and a high degree of influence: This group included $C_{10}$ (return) and $C_{6}$ (risk). These criteria are depicted as reason criteria and are the essential criteria impacting other criteria. Critical criteria with a low degree of significance and low degree of influence: this group comprised of $C_{8}$ (free float of stock) and $C_{1}$ (conservative capital structure). These criteria are impacted by other criteria so the degree of influence is very low, implying that the criteria under this category are not dependent. Criterion 10 (return) shows the highest correlation with other criteria because return is an influential criterion for stock portfolio selection in SSE. By way of contrast, criterion 8 (free float of stock) is the least correlated with other criteria.

The limit weights of ten criteria are computed by the proposed hybrid grey MCDM approach and shown in Table 11. It demonstrates that investors and decision makers are concerned with return, financial ratio, risk, and dividends. The criterion of return with 0.0328 has the highest value followed by financial ratio with a value of 0.0323 . According to Table 11 , the most important alternative is $A_{1}$ (Industrial and Commercial Bank of China Ltd.) with the highest priority of 0.1603 among the stocks selected from Shanghai Stock Exchange. From Eq. (13), an optimal way of allocating capital to the stocks considered in this study is as 
follows: Industrial and Commercial Bank of China Ltd. (22.9\%), China National Petroleum Corporation (20.5\%), China Yangtze Power Co. Ltd. (19.1\%), China Life Insurance Co. Ltd. (18.8\%), and Agricultural Bank of China Ltd. (18.7\%).

\section{Conclusions}

Firms and investors pursue stock portfolio selection as a key factor in achieving a favorable outcome and a better competitive position. Incorporating a multi-criteria decision-making $(\mathrm{MCDM})$ approach in a grey environment into the theory of portfolio selection is key in allocating wealth and ranking order of stocks under uncertainty. Decision makers or investors, want not only the ranking order of stocks but also the capital proportions to be allocated to stocks in a bid to attain sustainable development goals. The hybrid grey MCDM approach used in this study meets this objective.

This paper presented a novel approach by combining ANP and DEMATEL in a grey environment to provide both weighting and ranking information for decision-makers. The proposed approach was applied to the Shanghai Stock Exchange. Having reviewed existing literature and opinions of experts, decision-making criteria for stock portfolio selection were identified. The criteria selected were subjected to expert judgments to obtain pairwise comparison matrices with the aid of grey linguistic terms. The integrated grey-ANP and greyDEMATEL present a more robust and factual evaluation by incorporating interdependent relationships among and within decision-making criteria.

The findings of this study show that if the decision maker or investor wants a high reward, attention should be paid the cause group: return, financial ratios, dividends, and risk, as they are the most influential criteria in stock portfolio selection at SSE. The results also indicate that return and risk are reason criteria and are essential criteria controlling other criteria, and are effective determinants for stock portfolio selection in SSE. This is in line with the theory of MV analysis. Among the stocks understudy, stocks traded from Industrial and Commercial Bank of China Ltd. have the highest allocated proportion and can be described as the suitable alternative. The study highlights how grey system theory minimizes the uncertainties in all stages of decision-making of portfolio selection, considering financial theories.

The approach used in this study is established on expert judgments on asset features and criteria for stock selection. A probable imminent investigative approach would be to study, instead of prioritizing stocks based on random sampling, the entire portfolio of stocks listed on the exchange market, which could lead to a broader understanding from a financial viewpoint. This paper's approach may be extended for a portfolio that is made up of other assets under contrasting financial market conditions. It is also feasible to use results from different methods to compare the results of this model under the scope of efficiency or performance tests with the motivation of meeting sustainable development goals of 2030 .

\section{Acknowledgements}

The authors thank the editor and reviewers for their comments and suggestions. 


\section{Funding}

The authors acknowledge support from Management Science Project (Approval Number: 20192BAA208018) of Science and Technology Department of Jiangxi Province, China, 2019 high-level overseas talents returning project of Ministry of Human Resources and Social Security of the People's Republic of China, School of Economics \& Management, Jiangxi University of Science \& Technology, Ganzhou, China, and Ganzhou Academy of Financial Research (GAFR), Ganzhou, China.

\section{Author contributions}

Ebenezer Fiifi Emire Atta Mills, PhD conceived the study and was responsible for the design of the manuscript. Ebenezer Fiifi Emire Atta Mills, PhD, and Mavis Agyapomah Baafi were responsible for data collection and analysis. Ebenezer Fiifi Emire Atta Mills, PhD, Kailin Zeng, $\mathrm{PhD}$, and Nelson Amowine, $\mathrm{PhD}$ and were responsible for interpretation of results. Ebenezer Fiifi Emire Atta Mills, $\mathrm{PhD}$ and Nelson Amowine, $\mathrm{PhD}$ wrote the first draft of the manuscript. Ebenezer Fiifi Emire Atta Mills, PhD and Kailin Zeng, PhD were responsible for funding acquisition.

\section{Disclosure statement}

The authors declare no conflict of interest.

\section{References}

Abdel-Basset, M., Manogaran, G., Gamal, A., \& Smarandache, F. (2018). A hybrid approach of neutrosophic sets and DEMATEL method for developing supplier selection criteria. Design Automation for Embedded Systems, 22(3), 257-278. https://doi.org/10.1007/s10617-018-9203-6

Ahmed, N., \& Bassiouny, A. (2018). The effects of index changes on stock trading: Evidence from the EGX. Review of Economics \& Finance, 11, 55-66.

Asan, U., Soyer, A., \& Serdarasan, S. (2012) A fuzzy analytic network process approach. In C. Kahraman (Ed.), Computational intelligence systems in industrial engineering. Atlantis Computational Intelligence Systems (Vol. 6, pp. 155-179). Atlantis Press.

https://doi.org/10.2991/978-94-91216-77-0_8

Atta Mills, E. F. E., Yan, D., Yu, B., \& Wei, X. (2016). Research on regularized mean-variance portfolio selection strategy with modified Roy safety-first principle. SpringerPlus, 5(1), 919.

https://doi.org/10.1186/s40064-016-2621-7

Atta Mills, E. F. E., Yu, B., \& Yu, J. (2017). Scaled and stable mean-variance-EVaR portfolio selection strategy with proportional transaction costs. Journal of Business Economics and Management, 18(4), 561-584. https://doi.org/10.3846/16111699.2017.1342272

Bai, C., \& Sarkis, J. (2011). Evaluating supplier development programs with a grey based rough set methodology. Expert Systems with Applications, 38(11), 13505-13517. https://doi.org/10.1016/j.eswa.2011.02.137

Capelle-Blancard, G. (2017). Curbing the growth of stock trading? Order-to-trade ratios and financial transaction taxes. Journal of International Financial Markets, Institutions and Money, 49, 48-73. https://doi.org/10.1016/j.intfin.2017.02.004 
Charouz, J., \& Ramík, J. (2010). A multicriteria decision making at portfolio management. E+M Ekonomie a Management, (2), 44-52.

Cui, L., Chan, H. K., Zhou, Y., Dai, J., \& Lim, J. J. (2019). Exploring critical factors of green business failure based on Grey-Decision Making Trial and Evaluation Laboratory (DEMATEL). Journal of Business Research, 98, 450-461. https://doi.org/10.1016/j.jbusres.2018.03.031

Cuthbertson, K., \& Nitzsche, D. (2013). Performance, stock selection and market timing of the German equity mutual fund industry. Journal of Empirical Finance, 21, 86-101. https://doi.org/10.1016/j.jempfin.2012.12.002

Deng, J. L. (1982). Control problems of grey systems. Systems and Control Letters, 1(5), 288-294. https://doi.org/10.1016/S0167-6911(82)80025-X

Devpura, N., Narayan, P. K., \& Sharma, S. S. (2018). Is stock return predictability time-varying? Journal of International Financial Markets, Institutions and Money, 52, 152-172. https://doi.org/10.1016/j.intfin.2017.06.001

Ding, Y., \& Lu, Z. (2016). The optimal portfolios based on a modified safety-first rule with risk-free saving. Journal of Industrial \& Management Optimization, 12(1), 83-102. https://doi.org/10.3934/jimo.2016.12.83

Dou, Y., Zhu, Q., \& Sarkis, J. (2014). Evaluating green supplier development programs with a greyanalytical network process-based methodology. European Journal of Operational Research, 233(2), 420-431. https://doi.org/10.1016/j.ejor.2013.03.004

El-Nader, G. (2018). Stock liquidity and free float: Evidence from the UK. Managerial Finance, 44(10), 1227-1236. https://doi.org/10.1108/MF-12-2017-0494

Firth, M., Gao, J., Shen, J., \& Zhang, Y. (2016). Institutional stock ownership and firms' cash dividend policies: Evidence from China. Journal of Banking \& Finance, 65, 91-107. https://doi.org/10.1016/j.jbankfin.2016.01.009

Gabus, A., \& Fontela, E. (1972). World problems, an invitation to further thought within the framework of DEMATEL. Battelle Geneva Research Center. Geneva, Switzerland.

Garcia-Lopez, F. J., Batyrshin, I., \& Gelbukh, A. (2018). Analysis of relationships between tweets and stock market trends. Journal of Intelligent \& Fuzzy Systems, 34(5), 3337-3347. https://doi.org/10.3233/JIFS-169515

Gilbert, T., Scotti, C., Strasser, G., \& Vega, C. (2017). Is the intrinsic value of a macroeconomic news announcement related to its asset price impact? Journal of Monetary Economics, 92, 78-95. https://doi.org/10.1016/j.jmoneco.2017.09.008

Gupta, P., Mehlawat, M. K., \& Saxena, A. (2013). Hybrid optimization models of portfolio selection involving financial and ethical considerations. Knowledge-Based Systems, 37, 318-337. https://doi.org/10.1016/j.knosys.2012.08.014

Haleem, A., Khan, S., \& Khan, M. I. (2019). Traceability implementation in food supply chain: A greyDEMATEL approach. Information Processing in Agriculture, 6(3), 335-348. https://doi.org/10.1016/j.inpa.2019.01.003

He, Z., He, L., \& Wen, F. (2019). Risk compensation and market returns: The role of investor sentiment in the stock market. Emerging Markets Finance and Trade, 55(3), 704-718. https://doi.org/10.1080/1540496X.2018.1460724

Ho, W. R. J., Tsai, C. L., Tzeng, G. H., \& Fang, S. K. (2011). Combined DEMATEL technique with a novel MCDM model for exploring portfolio selection based on CAPM. Expert Systems with Applications, 38(1), 16-25. https://doi.org/10.1016/j.eswa.2010.05.058

Huang, D., Zhu, S. S., Fabozzi, F. J., \& Fukushima, M. (2008). Portfolio selection with uncertain exit time: A robust CVaR approach. Journal of Economic Dynamics and Control, 32(2), 594-623. https://doi.org/10.1016/j.jedc.2007.03.003 
Jakob, K., \& Whitby, R. (2017). The impact of nominal stock price on ex-dividend price responses. Review of Quantitative Finance and Accounting, 48(4), 939-953. https://doi.org/10.1007/s11156-016-0574-0

Karpavičius, S., \& Yu, F. (2018). Dividend premium: Are dividend-paying stocks worth more? International Review of Financial Analysis, 56, 112-126. https://doi.org/10.1016/j.irfa.2018.01.004

Kaur, J., Sidhu, R., Awasthi, A., Chauhan, S., \& Goyal, S. (2018). A DEMATEL based approach for investigating barriers in green supply chain management in Canadian manufacturing firms. International Journal of Production Research, 56(1-2), 312-332. https://doi.org/10.1080/00207543.2017.1395522

Kellerer, H., Mansini, R., \& Speranza, M. G. (2000). Selecting portfolios with fixed costs and minimum transaction lots. Annals of Operations Research, 99(1-4), 287-304. https://doi.org/10.1023/A:1019279918596

Kelly, B. T., Pruitt, S., \& Su, Y. (2019). Characteristics are covariances: A unified model of risk and return. Journal of Financial Economics, 134(3), 501-524. https://doi.org/10.1016/j.jineco.2019.05.001

Leung, L. C., Hui, Y. V., \& Zheng, M. (2003). Analysis of compatibility between interdependent matrices in ANP. Journal of the Operational Research Society, 54(7), 758-768. https://doi.org/10.1057/palgrave.jors.2601569

Li, Y., \& Mathiyazhagan, K. (2018). Application of DEMATEL approach to identify the influential indicators towards sustainable supply chain adoption in the auto components manufacturing sector. Journal of Cleaner Production, 172, 2931-2941. https://doi.org/10.1016/j.jclepro.2017.11.120

Lin, R. J. (2013). Using fuzzy DEMATEL to evaluate the green supply chain management practices. Journal of Cleaner Production, 40, 32-39. https://doi.org/10.1016/j.jclepro.2011.06.010

Liu, J., \& Qiao, J. Z. (2014). A grey rough set model for evaluation and selection of software cost estimation methods. Grey Systems: Theory and Application, 4(1), 3-12. https://doi.org/10.1108/GS-08-2013-0016

Luthra, S., Govindan, K., Kharb, R. K., \& Mangla, S. K. (2016). Evaluating the enablers in solar power developments in the current scenario using fuzzy DEMATEL: An Indian perspective. Renewable and Sustainable Energy Reviews, 63, 379-397. https://doi.org/10.1016/j.rser.2016.04.041

Mandic, K., Delibasic, B., Knezevic, S., \& Benkovic, S. (2014). Analysis of the financial parameters of Serbian banks through the application of the fuzzy AHP and TOPSIS methods. Economic Modelling, 43, 30-37. https://doi.org/10.1016/j.econmod.2014.07.036

Markowitz, H. (1952). Portfolio selection. The Journal of Finance, 7(1), 77-91. https://doi.org/10.1111/j.1540-6261.1952.tb01525.x

Opricovic, S., \& Tzeng, G. H. (2003). Defuzzification within a multicriteria decision model. International Journal of Uncertainty, Fuzziness and Knowledge-Based Systems, 11(05), 635-652. https://doi.org/10.1142/S0218488503002387

Patel, J., Shah, S., Thakkar, P., \& Kotecha, K. (2015). Predicting stock and stock price index movement using trend deterministic data preparation and machine learning techniques. Expert Systems with Applications, 42(1), 259-268. https://doi.org/10.1016/j.eswa.2014.07.040

Pourjavad, E., \& Shahin, A. (2018). Hybrid performance evaluation of sustainable service and manufacturing supply chain management: An integrated approach of fuzzy dematel and fuzzy inference system. Intelligent Systems in Accounting, Finance and Management, 25(3), 134-147. https://doi.org/10.1002/isaf.1431

Rahimnia, F., Moghadasian, M., \& Mashreghi, E. (2011). Application of grey theory approach to evaluation of organizational vision. Grey Systems: Theory and Application, 1(1), 33-46. https://doi.org/10.1108/20439371111106713

Rezaeian, J., \& Akbari, F. (2015). Stock portfolio selection using a hybrid fuzzy approach: A case study in Tehran Stock Exchange. International Journal of Operational Research, 22(4), 423-453.

https://doi.org/10.1504/IJOR.2015.068560 
Roy, A. D. (1952). Safety first and the holding of assets. Econometrica, 20(3), 431-449. https://doi.org/10.2307/1907413

Saaty, T. L. (1990). How to make a decision: the analytic hierarchy process. European Journal of Operational Research, 48(1), 9-26. https://doi.org/10.1016/0377-2217(90)90057-I

Saaty, T. L. (1996). Decision making with dependence and feedback: The Analytic Network Process (Vol. 4922). RWS Publications (accessed 18 December 2018). https://ci.nii.ac.jp/naid/10018484540/

Saaty, T. L. (1980). The analytic hierarchy process: Planning, priority setting, resources allocation. McGraw-Hill.

Seçme, N. Y., Bayrakdaroğlu, A., \& Kahraman, C. (2009). Fuzzy performance evaluation in Turkish banking sector using analytic hierarchy process and TOPSIS. Expert Systems with Applications, 36(9), 11699-11709. https://doi.org/10.1016/j.eswa.2009.03.013

Shanghai Stock Exchange. (2019). SSE Monthly Market Statistics. http://english2019.sse.com.cn/indices/ publications/monthly/

Simaan, M., Simaan, Y., \& Tang, Y. (2018). Estimation error in mean returns and the mean-variance efficient frontier. International Review of Economics \& Finance, 56, 109-124. https://doi.org/10.1016/j.iref.2017.10.019

Tian, G., Liu, X., Zhang, M., Yang, Y., Zhang, H., Lin, Y., Ma, F., Wang, X., Qu, T., \& Li, Z. (2019). Selection of take-back pattern of vehicle reverse logistics in China via Grey-DEMATEL and FuzzyVIKOR combined method. Journal of Cleaner Production, 220, 1088-1100. https://doi.org/10.1016/j.jclepro.2019.01.086

Vercher, E., Bermúdez, J. D., \& Segura, J. V. (2007). Fuzzy portfolio optimization under downside risk measures. Fuzzy Sets and Systems, 158(7), 769-782. https://doi.org/10.1016/j.fss.2006.10.026

Wang, X. T., Li, Z., \& Zhuang, L. (2017). Risk preference, option pricing and portfolio hedging with proportional transaction costs. Chaos, Solitons \& Fractals, 95, 111-130. https://doi.org/10.1016/j.chaos.2016.12.010

Wu, S. I., \& Hung, J. M. (2008). A performance evaluation model of CRM on non-profit organisations. Total Quality Management, 19(4), 321-342. https://doi.org/10.1080/14783360701591978

Xia, X., Govindan, K., \& Zhu, Q. (2015). Analyzing internal barriers for automotive parts remanufacturers in China using grey-DEMATEL approach. Journal of Cleaner Production, 87, 811-825. https://doi.org/10.1016/j.jclepro.2014.09.044

Zhu, J. (2017). Optimal financing and dividend distribution with transaction costs in the case of restricted dividend rates. ASTIN Bulletin: The Journal of the IAA, 47(1), 239-268. https://doi.org/10.1017/asb.2016.29 